\title{
Specifying the Mechanisms and Targets of Emotion Regulation: A Translational Framework from Affective Science to Psychological Treatment
}

\author{
Matthew W. Southward ${ }^{1}$, Shannon Sauer-Zavala ${ }^{1}$, and Jennifer S. Cheavens ${ }^{2}$ \\ ${ }^{1}$ Department of Psychology, University of Kentucky \\ ${ }^{2}$ Department of Psychology, The Ohio State University
}

\begin{abstract}
Author Note
Matthew W. Southward: https://orcid.org/0000-0002-5888-2769

Shannon Sauer-Zavala: https://orcid.org/0000-0002-7322-983X

Jennifer S. Cheavens: https://orcid.org/0000-0002-3778-9346

Correspondence concerning the article should be addressed to Matthew W. Southward, Department of Psychology, University of Kentucky; 343 Waller Ave., Suite 303, Lexington, KY 40504. Phone 859-562-1569. Email: southward@uky.edu
\end{abstract}

In press at Clinical Psychology: Science and Practice

(C) 2021, American Psychological Association. This paper is not the copy of record and may not exactly replicate the final, authoritative version of the article. Please do not copy or cite without authors' permission. The final article will be available, upon publication, via its DOI: $10.1037 /$ cps0000003 


\title{
EMOTION REGULATION TRANSLATIONAL FRAMEWORK
}

\author{
Abstract \\ Emotion dysregulation is fundamental to a range of psychiatric disorders. Leading \\ psychological treatments are often designed to teach several emotion regulation strategies. \\ However, teaching a wide range of strategies may be an inefficient way to enhance emotional \\ functioning. We propose a framework of emotion dysregulation to guide the development of \\ more efficient and flexible interventions. We review motivational (i.e., self-efficacy), between- \\ situation (i.e., increasing frequency, quantity, or quality of adaptive strategy use; decreasing \\ frequency of maladaptive strategy use), and within-situation mechanisms (i.e., using more or \\ fewer strategies in a given situation; optimally ordering strategies) as well as temporal targets of \\ emotion regulation interventions (i.e., short-term effectiveness vs. long-term adaptiveness). \\ Throughout, we detail recommendations for researchers to test these mechanisms and targets. \\ Keywords: emotion regulation; treatment; adaptiveness; quality; self-efficacy
}

\section{Public Health Statements}

- Emotion dysregulation is a fundamental component of psychiatric disorders, but its active mechanisms remain poorly defined.

- We propose a framework to define these mechanisms that involves immediate, as well as long-term, emotional and clinical outcomes.

- Clarifying these mechanisms can lead to the development of more efficient, optimized, and personalized psychological interventions. 


\section{Specifying the Mechanisms and Targets of Emotion Regulation: A Translational Framework from Affective Science to Psychological Treatment}

Emotion regulation is the process by which people influence the onset, intensity, and/or duration of their emotions (Gross \& Thompson, 2007). Emotion dysregulation, on the other hand, is defined as the limited use of adaptive emotion regulation strategies or overuse of maladaptive strategies in response to a biological sensitivity to experience more intense emotions (Kring \& Sloan, 2010; Linehan, 1993; Neacsiu et al., 2013), and may contribute to the etiology and maintenance of many common psychiatric disorders (Aldao et al., 2010; 2016). Accordingly, most psychological treatments for common mental health conditions aim to decrease emotion dysregulation by enhancing emotion regulation (Gratz et al., 2015; Sloan et al., 2017). Cognitivebehavioral interventions, in particular, focus on teaching patients an array of emotion regulation strategies to influence their affective experiences.

Clarifying how emotion regulation influences psychopathology and determining the most efficacious ways to enhance patients' emotion regulation capacities are core targets for researchers aiming to improve treatment outcomes. However, the process of emotion regulation is complex, with effects occurring at multiple levels of analysis (Figure 1). For example, discrete strategies aimed at influencing an emotional experience (e.g., problem-solving, thought suppression) may exert different effects over relatively shorter and longer timescales. In the short term (i.e., within about 1-2 hours after regulation), emotion regulation strategies may be effective, defined as the degree to which a strategy helps a person "reach their desired emotional outcomes" (Ford et al., 2019) - usually a reduction in negative affect immediately after its use (Webb et al., 2012). Strategies that consistently promote these immediate desired outcomes can be classified as effective, while those that do not can be classified as ineffective. Over the longer 
term (i.e., on the scale of days, months, or years), emotion regulation strategies may demonstrate adaptiveness, conceptualized as the degree to which the habitual use of a strategy "is associated with better longer-term outcomes" (Ford et al., 2019). These outcomes commonly include personality functioning (Gross \& John, 2003; Southward et al., 2018), general well-being (Birk \& Bonanno, 2016; Gross \& John, 2003), or symptoms of psychopathology (Aldao et al., 2010). Strategies associated with better long-term psychological functioning can be classified as adaptive, while those that tend to promote worse outcomes can be classified as maladaptive. We recognize that a host of contextual factors (e.g., biological, developmental, environmental, and individual difference factors - see Contextual Factors section below) can influence the effectiveness and adaptiveness of strategies in specific instances (Aldao, 2013; Bonanno \& Burton, 2013). However, classifying strategies by their effectiveness and adaptiveness is a useful heuristic for summarizing this literature, given that treatments most often promote the use of relatively adaptive strategies, and this classification, as a data-driven approach, can facilitate communication and translation between basic affective science and intervention research.

In addition to clarifying the relation between discrete emotion regulation strategies and outcomes, it is also unclear how best to enhance patients' emotion regulation capacities in treatment. To date, most basic affective science and intervention research has focused on a combination of the quantity and frequency with which strategies are used. The quantity of emotion regulation strategies a person uses over time has been referred to as a person's emotion regulation repertoire (Bonanno \& Burton, 2013; Cheng et al., 2014), indicating the number of unique strategies a person has used, assessed by behavioral demonstration (Bonanno et al., 2004) or self-report (Southward et al., 2018). The frequency of strategy use, in contrast, refers to how often a person uses emotion regulation strategies, regardless of whether those strategies are the 
same or different. In an extreme example, a person could exhibit low strategy quantity, because they only use one strategy, but high strategy frequency, because they regularly use this strategy.

Beyond quantity and frequency of adaptive skill use, two alternative ways emotion regulation may influence outcomes include improvements in the quality with which adaptive emotion regulation strategies are used, as well as reductions in the frequency of use of maladaptive strategies. We define quality as how well a person uses emotion regulation strategies in line with how the strategy was taught or conceptualized. For instance, whereas a low quality cognitive reappraisal in response to the negative thought "I'm worthless" may be "I'm not worthless," a high quality reappraisal may be "Every human, including me is inherently worthwhile - furthermore, I'm a committed partner who works hard at my job and cares for people in my community." Quality is often measured by human raters trained to a set of standards. In basic affective science research, raters often use manualized codebooks (e.g., Barber \& DeRubeis, 1992). In treatment, therapists often function as raters to assess how well patients' skill use matches how the therapist taught the skill. It is important to note that the quality with which a strategy is used is distinct from its effects on emotional outcomes. That is, how well a person uses an emotion regulation strategy should not be conflated with changes in emotional outcomes to preserve the distinction between process and outcome.

Finally, as noted previously, adaptive strategies may be distinguished from maladaptive strategies, defined as emotion regulation strategies associated with worse long-term functioning. Improvements in psychological health may be more strongly associated with the decreased use of maladaptive strategies, rather than increases in the quantity, frequency, or quality of adaptive strategies (Conklin et al., 2015). Thus, identifying which methods of improving patients' emotion regulation capacities in treatment are associated with the greatest effects on long-term 
outcomes is necessary to make existing interventions more efficient and targeted.

The goal of the present paper is to examine current controversies in treatment-oriented emotion regulation research by providing a translational framework that connects basic affective science and intervention research and synthesizes different levels of analysis that should be considered when targeting emotion dysregulation in treatment (Figure 1). This framework is meant to complement current influential models of the process of emotion regulation (Ford et al., 2019; Gross, 2015), emotion regulation flexibility (Bonanno \& Burton, 2013), and emotion dysregulation (Carpenter \& Trull, 2013) by explicitly focusing on how to improve patients' emotion regulation processes in a treatment context. We first review evidence regarding the effects of increasing the frequency and quantity of adaptive strategies used on emotional outcomes, as the majority of treatment-oriented research has focused on this operationalization. We then consider emerging evidence regarding the importance of the quality with which adaptive strategies are used, along with the case for focusing on reducing the frequency of maladaptive strategies. Next, we distinguish the timescale of these effects by differentiating emotion regulation adaptiveness from effectiveness. We use this distinction to explore patterns of emotion regulation strategy use within and across situations, and whether the order in which strategies are used impacts psychological health. Finally, we provide an overview of the role of emotion regulation self-efficacy as a motivational mechanism that may strengthen the previously reviewed constructs and be necessary for their optimal functioning. Throughout, we propose testable hypotheses for a research agenda to better clarify each domain.

\section{Increasing the Quantity, or Repertoire, of Adaptive Emotion Regulation Strategies}

\section{Affective Science Research}

A substantial body of evidence supports the idea that people who use a greater number of 
different adaptive emotion regulation strategies tend to have better psychological health, although meta-analytic estimates of this effect are modest, $r=.12$ (Cheng et al., 2014). This effect size may underestimate the strength of the association, however, because it includes participants' use of putatively adaptive and maladaptive strategies. By distinguishing classes of strategies, two ecological momentary assessment (EMA) studies of undergraduate students have demonstrated a more consistent link between strategy repertoires and adaptiveness. Larger repertoires of adaptive strategies were related to better emotional well-being, less negative affect, dysphoria, and social anxiety but larger repertoires of maladaptive strategies were related to worse emotional well-being (McMahon \& Naragon-Gainey, 2019; Southward et al., 2020). Similarly, when clustered into regulatory groups, people who used a greater number of adaptive strategies and fewer maladaptive strategies reported fewer symptoms of depression, anxiety, social anxiety, and borderline personality disorder (BPD) than participants who used more adaptive and maladaptive strategies (Dixon-Gordon et al., 2014).

One caveat to this line of research is the repeated finding that more intense momentary emotions tend to prompt the use of more emotion regulation strategies (Ford et al., 2019). When using retrospective recall (Dixon-Gordon, Aldao, \& de los Reyes, 2015), directly engaging with a disgust-eliciting video (Aldao \& Nolen-Hoeksema, 2013), or viewing negatively-valenced images (Optiz et al., 2015), people used a greater variety of adaptive and maladaptive strategies in response to more intense momentary negative emotions. In combination with the previous results, these findings may suggest that more intense negative emotions prompt people to use more emotion regulation strategies in the hopes of finding the "right" one (Aldao et al., 2015; Southward et al., 2018). Alternatively, because emotions are holistic (i.e., cognitive, affective, behavioral, and physiological) responses, more intense emotions may require a wider variety of 
strategies to address each domain. Resolving the discrepancy between momentary and repeated emotion regulation use is an important target in understanding optimal emotion regulation.

However, it is also important to consider contextual factors influencing the relation between emotion intensity and strategy use. For instance, compared to those with greater psychopathology, people with lower levels of psychopathology may use a greater number or proportion of adaptive strategies in these situations; they may use their strategies more effectively; or they may have fewer vulnerability factors and external stressors to allow a faster return to baseline emotional functioning. People with more emotion regulation goals in a given situation may also need to leverage more strategies to achieve each of these goals. Alternatively, certain situational contexts may be more dynamic (e.g., an argument with a partner) than others (e.g., not receiving a raise) and thus require a wider variety of strategies. Examining these contexts, both in a given situation and across situations, can offer greater nuance to clarify the conditions in which a larger repertoire of strategies is ultimately beneficial.

\section{Intervention Research}

Because many of the measures used with clinical samples ask respondents to rate how frequently they use emotion regulation strategies (e.g., COPE; Carver et al., 1989; Dialectical Behavior Therapy - Ways of Coping Checklist; Neacsiu, Rizvi, Vitaliano et al., 2010; Ways of Coping Questionnaire; Folkman \& Lazarus, 1988) and have not been scored to capture emotion regulation repertoires, there is no research to our knowledge on changes in the quantity of strategies used in treatment studies. This would be a straightforward and important area for future researchers to consider, because nearly all common measures of emotion regulation frequency include a response option indicating that participants did not use that strategy. Future researchers are encouraged to calculate and report the number of unique strategies patients use 
across treatment to determine (a) if the size or composition of participants' emotion regulation repertoires changes over treatment and (b) if these changes mediate clinical outcomes.

\section{Increasing the Frequency of Adaptive Emotion Regulation Strategies}

\section{Affective Science Research}

Compared to people with depressive, anxiety, and personality disorders, people without psychopathology use adaptive emotion regulation strategies more frequently (Daros et al., 2019; Lukas et al., 2018; Neacsiu \& Tkachuck, 2016; Southward \& Cheavens, 2020b; Thompson et al., 2010; Vitaliano et al., 1987). These results suggest that more frequent use of adaptive emotion regulation strategies is related to better psychological health.

\section{Intervention Research}

Numerous cognitive-behavioral treatments have been developed with an explicit focus on emotion dysregulation, including Affect Regulation Training (ART; Berking \& Lucas, 2015), Dialectical Behavior Therapy (DBT; Linehan, 1993), Emotion Regulation Group Therapy (ERGT; Gratz \& Gunderson, 2006), Emotion Regulation Therapy (Renna et al., 2017), and the Unified Protocol for Transdiagnostic Treatment of Emotional Disorders (UP; Barlow et al., 2018). These treatments are designed to teach patients a range of adaptive emotion regulation strategies that they can use frequently. Although these dual goals make it difficult to tease apart the unique effects of strategy quantity and frequency on emotional health, these treatments have demonstrated efficacy in reducing symptoms of depression, anxiety, BPD, eating disorders, and self-harm behaviors (Berking et al., 2019; Cristea et al., 2017; Dixon-Gordon, Chapman, \& Turner, 2015; Gratz et al., 2014; Neacsiu et al., 2014; Renna et al., 2017; Sakiris \& Berle, 2019; Uliaszek et al., 2016; Valentine et al., 2015).

One of the most convincing ways to demonstrate the unique effects of adaptive emotion 
regulation strategies on emotional and behavioral outcomes is to conduct component analyses in which an empirically-based treatment enhanced with emotion regulation skills training is compared to the same treatment without this enhancement (Cuijpers et al., 2019). Five such component analyses have been conducted. In these studies, emotion regulation skills training led to greater improvements in depression symptoms, positive affect, and negative affect in two inpatient samples (Berking et al., 2008; 2013) and greater reductions in non-suicidal self-injury (NSSI) behaviors, depressive and anxiety symptoms, crisis service utilization, and dropout in outpatient samples (Gratz \& Gunderson, 2006; Gratz et al., 2014; Linehan et al., 2015).

Despite these relatively consistent findings, the evidence that more frequent use of adaptive emotion regulation strategies mediates treatment outcomes is mixed. In three studies of inpatients receiving individual and group-based cognitive-behavior therapy (CBT) and related activities, more frequent use of adaptive and behavioral strategies predicted decreases in depressive symptoms (Radkovsky et al., 2014; Webb et al., 2016; Wirtz et al., 2014), while more frequent use of DBT strategies predicted decreases in anxiety symptoms (Webb et al., 2016). More frequent use of adaptive emotion regulation strategies also mediated the effect of time in treatment on changes in suicide attempts, NSSI behaviors, control over anger expressions, and depressive symptoms among patients with BPD in DBT and an active control treatment (Neacsiu, Rizvi, \& Linehan, 2010). However, in an independent study of outpatients with BPD in DBT, more frequent within-person adaptive emotion regulation strategy use was associated with increases in social impairment but unrelated to interpersonal or global functioning (Wilks et al., 2016). Among patients with elevated emotion dysregulation in a 12-week positive psychotherapy skills group, more frequent use of adaptive strategies was associated with worsening self-reported BPD features at mid-treatment (Uliaszek et al., 2018). 
Together, these treatment findings suggest that patients who use adaptive emotion regulation strategies more frequently tend to have better psychological health. Further, treatments designed to teach patients a variety of adaptive emotion regulation strategies led to improvements in psychological health. These results provide evidence for the assumption that the more frequent use of strategies promotes better psychological outcomes. However, it is less clear from these studies whether more frequent use of adaptive strategies is a mechanism by which these treatments exert their effects. This question is especially salient given that treatments designed to enhance patients' repertoires of adaptive emotion regulation strategies (e.g., DBT) demonstrated the most mixed findings, whereas CBT-based treatments that teach relatively fewer strategies produced more consistent results. These results open the door for researchers to test alternative explanations for the effects of these treatments, which we elaborate on below.

\section{Enhancing the Quality of Adaptive Emotion Regulation Skills}

\section{Affective Science Research}

As researchers have noted, the frequency of strategy use is "a proxy for skillful behavior" (Neacsiu, Rizvi, \& Linehan, 2010). Skillful behavior, or the quality of one's strategy use, can be defined as how well a person uses a strategy in accordance with how it was conceptualized and taught, regardless of whether or not it leads to the intended outcome. For instance, whereas a higher quality form of problem-solving may involve a larger number of specific, goal-relevant ideas a person could pursue, lower quality problem-solving may only involve one or two vague or impractical plans. Although we typically assume people engage in behaviors more frequently if they are already skilled at using them, skillfulness, or quality, can be distinguished from frequency. One common measure of emotion regulation quality is the Ways of Responding Scale (WOR; Barber \& DeRubeis, 1992). The WOR presents respondents with six hypothetical 
stressful scenarios accompanied by negative thoughts a person may have in each. Respondents are asked to write what further thoughts they would have in that scenario, beyond those already prompted, and what behaviors they may engage in. Independent coders then rate the quality of responses. Across studies of participants without psychopathology and those with major depressive disorder (MDD) or BPD, the quality of participants' emotion regulation strategies exhibited medium-sized positive associations ( $r$ s: .21-.44) with the frequency of their strategy use (Barber \& DeRubeis, 1992; Southward \& Cheavens, 2020b).

Given the distinction between frequency and quality of emotion regulation strategy use, researchers have investigated the unique relations between emotion regulation quality and emotional outcomes. The quality with which people use expressive regulation (i.e., suppressing or enhancing one's facial expression of emotion) has been associated with lower posttraumatic stress disorder (PTSD) and depressive symptoms among combat veterans (Rodin et al., 2017). Expressive regulation quality has also predicted changes in anxiety and depressive symptoms months (Southward \& Cheavens, 2017) and years later (Bonanno et al., 2004; Westphal et al., 2010) in independent undergraduate samples (cf. Zhu \& Bonanno, 2017). Similarly, higher quality reappraisal, as measured by the WOR, has been associated with greater well-being and less depressive reactivity to stressful life events in undergraduates (Adler et al., 2013; Barber \& DeRubeis, 1992) and lower depressive symptoms among those with MDD (Barber \& DeRubeis, 1992). People with BPD demonstrated lower emotion regulation quality than those with MDD, who in turn demonstrated lower quality than those without psychopathology (Southward \& Cheavens, 2020b). Together, these results highlight the added value in assessing not only how frequently people use emotion regulation strategies but how well they use them.

\section{Intervention Research}


The majority of treatment research on emotion regulation quality has been conducted on cognitive therapy of depression (CT; Beck et al., 1979; Hundt et al., 2013). Higher quality emotion regulation strategies in treatment have generally been associated with and predicted lower depression scores (Adler et al., 2015; Barber \& DeRubeis, 2001; Forand et al., 2018; Manber et al., 2003; Neimeyer et al., 2008; Strunk et al., 2014; cf. Neimeyer \& Feixas, 1990). Higher quality use of emotion regulation strategies even predicted a lower risk of relapse 6-15 months post-treatment (Kuyken et al., 2010; Neimeyer \& Feixas, 1990; Strunk et al., 2007). Together, these results suggest that improving the quality with which strategies are used may be an important target in CT for depression.

Given the focus on emotion regulation strategy quality in the context of CT, it is unclear how well these results generalize to (a) emotion regulation strategies beyond cognitive restructuring, (b) psychotherapy treatments beyond CT, and (c) outcomes beyond depressive symptoms. Further, researchers have not, to our knowledge, compared the relative benefits of emotion regulation strategy quality and frequency in the same treatment study. It is possible that treatments designed to teach a wide variety of strategies activate different mechanisms than treatments designed to teach one or two strategies more thoroughly. Treatments designed to teach a wide variety of strategies may lead to decreases in psychopathology symptoms by increasing the number of adaptive strategies and decreasing the number of maladaptive strategies patients use. On the other hand, treatments designed to teach one or two strategies thoroughly may lead to symptom change by enhancing the quality of those few strategies. Alternatively, quality and frequency of use may interact with each other. For instance, using particular strategies often may only produce symptom change if those strategies are used well. This hypothesis suggests that patients should only learn additional emotion regulation strategies after 
they have demonstrated competence with previous strategies, or it has been determined that the patient does not have the capability to use previous strategies with that level of competence, rather than strictly adhering to a predefined schedule of skill delivery (Swales \& Dunkley, 2019).

\section{Decreasing Maladaptive Emotion Regulation Strategy Use}

\section{Affective Science Research}

Rather than increasing the frequency of adaptive emotion regulation strategy use, it may be more useful to prioritize reductions in maladaptive strategies. Individual maladaptive strategies have demonstrated stronger meta-analytic associations with symptoms of depression, anxiety, substance use, and eating disorders (average $r=.40$ ) than adaptive strategies (average $r$ $=-.21$; Aldao et al., 2010). Similarly, people without psychopathology tend to use maladaptive strategies less frequently than people with depressive, anxiety, and personality disorders (Daros et al., 2019; Neacsiu \& Tkachuck, 2016; Southward \& Cheavens, 2020b; Vitaliano et al., 1987). Together, these results suggest that the more frequent use of maladaptive strategies is more strongly linked with negative affect and psychopathology than the use of adaptive strategies. Maladaptive strategies may thus have a more direct connection to psychopathology than adaptive strategies that is analogous to physical regulation strategies. For instance, consuming a large meal will lead to weight gain more directly than exercise will contribute to weight loss. In the same way, maladaptive strategies, such as rumination, may more directly lead to feelings of depression than adaptive strategies, such as reappraisal, which may influence feelings of depression by means of new cognitive interpretations of a situation.

\section{Intervention Research}

Treatments targeting emotion dysregulation, such as DBT and DBT groups, have led to decreases in patients' use of maladaptive emotion regulation strategies (Flynn et al., 2018; 
Moore et al., 2018; Muhomba et al., 2017). These decreases are often greater than in other active treatments (Cristea et al., 2017; Chugani et al., 2013; Linehan et al., 2015; Uliaszek et al., 2018).

Only three studies to our knowledge have directly compared the relative impact of the use of adaptive and maladaptive strategies. Among college students with elevated emotion dysregulation in a DBT skills group, decreases in maladaptive strategy use were associated with fewer depressive and BPD symptoms by the end of treatment (Uliaszek et al., 2018). However, among students in a positive psychotherapy skills group, adaptive strategy use was associated with greater BPD symptoms at mid-treatment. This may suggest that using more strategies to regulate one's emotions, even when they are adaptive, may be a form of "flailing" for the right strategy in treatments not specifically designed to teach a range of strategies. Among patients in eight treatments ${ }^{1}$ for mood, anxiety, and personality disorders, patients' use of maladaptive strategies decreased across treatment, while patients' use of adaptive strategies remained unchanged (Gibbons et al., 2009). Greater decreases in maladaptive strategies were related to greater improvements in anxiety and depressive symptoms and quality of life. Finally, among patients with comorbid alcohol use and anxiety disorders receiving the UP or progressive muscle relaxation combined with placebo or venlafaxine, decreases in maladaptive strategy use were significantly associated with decreases in psychopathology, whereas increases in adaptive strategy use were unrelated to changes in psychopathology (Conklin et al., 2015). These effects were qualified by an interaction between maladaptive strategy use at baseline and changes in adaptive strategy use across treatment. Increases in adaptive strategy use were associated with decreases in psychopathology among patients who reported using maladaptive strategies

\footnotetext{
${ }^{1}$ Alliance-fostering therapy for depression; schema-focused cognitive therapy for BPD; relationship-focused therapy for panic disorder; cognitive therapy for panic disorder; compensatory cognitive skills therapy for adolescent anxiety; compensatory cognitive skills therapy plus family therapy for adolescent anxiety; supportive-expressive therapy for generalized anxiety disorder (GAD); supportive therapy for GAD
} 
relatively more frequently at baseline. However, changes in adaptive strategy use were unrelated to changes in psychopathology among those who reported using maladaptive strategies relatively less frequently at baseline, suggesting that patients' use of maladaptive strategies may be an important individual difference to consider in emotion regulation-focused treatments.

Taken together, these results suggest that using maladaptive strategies more frequently may be more strongly associated with psychopathology than the frequency with which adaptive strategies are used. These results imply that it may be more efficacious to directly target reductions in maladaptive strategies in treatment. Alternatively, these results may imply that teaching patients a wide variety of adaptive strategies leads to decreases in psychopathology by reducing the frequency with which patients use maladaptive strategies. We encourage researchers to test this hypothesis by assigning patients to either learn a wide variety of adaptive strategies or inhibit their use of maladaptive strategies, while measuring naturalistic adaptive and maladaptive strategy use and quality. Researchers should be careful not to conflate maladaptive strategies with measures of psychopathology. For instance, worry may be conceptualized as a maladaptive emotion regulation strategy but it is also a core symptom of generalized anxiety disorder (GAD). Thus, it is possible the results reviewed thus far are inflated by measuring items as both maladaptive strategies and psychopathology. We encourage researchers to be mindful of this overlap when designing studies so as to distinguish between these interrelated constructs.

\section{Temporal Dimensions of Emotion Regulation}

\section{Promoting Short-Term Effectiveness or Long-Term Adaptiveness}

Because effectiveness and adaptiveness are distinguishable, individual emotion regulation strategies may be categorized as any combination of effective and adaptive (e.g., acceptance; Aldao et al., 2010; Southward et al., 2019), effective and maladaptive (e.g., 
distraction; Sheppes \& Gross, 2011; NSSI; Klonsky, 2007; suppression; Aldao et al., 2010;

Webb et al., 2012), ineffective and adaptive (e.g., problem-solving; Aldao et al., 2010; Haines et al., 2016; Heiy \& Cheavens, 2014), and ineffective and maladaptive (e.g., rumination; Aldao et al., 2010; Heiy \& Cheavens, 2014). Categorizing strategies by their relative effectiveness and adaptiveness highlights how some strategies (e.g., expressive suppression), if used habitually, are often related to less adaptive psychological outcomes (Gross \& John, 2003), but if used strategically, are related to more effective momentary emotional outcomes (Webb et al., 2012). Similarly, whereas the habitual use of NSSI is related to maladaptive outcomes including higher rates of comorbid psychiatric disorders (Cipriano et al., 2017) and suicidality (Klonsky et al., 2013), the momentary use of NSSI is related to effective reductions in negative affect (Hamza \& Willoughby, 2015). Finally, habitual substance use is also related to maladaptive outcomes such as social withdrawal, liver disease, and sexual dysfunction (O'Brien, 2011), whereas substance use is often associated with momentary gregariousness and positive emotions (O’Brien, 2011). On the other hand, people who typically use problem-solving report more adaptive (i.e., lower) levels of psychopathology (Aldao et al., 2010), but problem-solving may be relatively ineffective in that it is unrelated to momentary affective responses (Heiy \& Cheavens, 2014).

\section{Intervention Research}

Given that psychological treatment is focused on enhancing patients' adaptive functioning, it is not surprising that providers more frequently recommend the use of putatively adaptive strategies as opposed to effective strategies (Southward et al., 2020). However, it may still be necessary to use effective but maladaptive strategies, such as distraction, to help patients tolerate extreme negative affect in specific situations (e.g., ignoring distress associated with an interpersonal conflict while studying for an upcoming exam). Therapists may practice this with 
patients in session or encourage them to use these strategies in high intensity emotional situations. This example highlights two timescales on which to consider emotion regulation effectiveness in treatment: (1) the effects of in-session emotion regulation strategy use on pre- to post-session changes in affect, and (2) the effects of momentary emotion regulation strategy use on immediate changes in affect outside of sessions.

Effectiveness. Assessing in-session changes in affect in response to emotion regulation skill use is important for at least two reasons. First, it can allow therapists to more directly gauge patients' emotion regulation skills. Second, researchers have provided preliminary evidence that greater experiencing of in-session affect, when combined with cognitive processing, may predict reductions in depressive symptoms in CBT (Aafjes-van Doorn \& Barber, 2017). Assessing insession skill use and affective changes can thus complement patients' reports of between-session effectiveness, providing a more comprehensive, multimethod account of these relations.

One study to our knowledge has assessed the effectiveness of patients' daily use of emotion regulation strategies on momentary changes in emotional outcomes (McMahon \& Naragon-Gainey, 2019). Among adult patients in community treatment, the within-person use of putatively adaptive strategies was unrelated to emotional outcomes, whereas the within-person use of more maladaptive strategies was related to increased momentary negative affect, dysphoria, social anxiety, worry, and panic and decreased momentary positive affect. These results highlight that patients' use of fewer maladaptive strategies may have the largest impact on their momentary emotional experiences. Future researchers are encouraged to replicate these results in treatments designed to teach specific emotion regulation skills. Given that patients in this study were receiving various forms of treatment, it is possible that the null findings regarding adaptive strategies resulted from patients not learning strategies in a systematic way. 
Adaptiveness. Adaptiveness may be measured on three distinct time scales in intervention research: (1) session-to-session, (2) pre- to post-treatment, and (3) follow-up. That is, emotion regulation strategies may be considered adaptive if they (1) predict session-to-session symptom changes, (2) predict pre- to post-treatment symptom changes, or (3) predict rates of relapse or recurrence over a follow-up period. Treatments based primarily on single emotion regulation strategies, such as cognitive reappraisal (Cuijpers et al., 2013), behavioral activation (Ekers et al., 2014), and mindfulness (Khoury et al., 2013) have shown evidence of adaptiveness at each of these time scales. However, finer-grained analyses of skill use and quality may be needed to clearly distinguish the unique effects of emotion regulation strategies from common treatment elements. For instance, the quality of patients' cognitive reappraisal skills and the frequency with which patients examined their core beliefs predicted a lower risk of relapse one year after cognitive therapy, over and above self-esteem at the end of treatment (Strunk et al., 2007). Studies such as these provide strong empirical evidence for the adaptive nature of these specific emotion regulation strategies.

Several studies have tested the adaptiveness of emotion regulation strategies on sessionto-session symptom changes. Strategies such as cognitive reappraisal (Conklin \& Strunk, 2015; Schmidt et al., 2019) and behavioral activation (Webb et al., 2016; 2019) predicted session-tosession reductions in depressive symptoms, while DBT skills predicted session-to-session reductions in anxiety symptoms (Webb et al., 2016). By teaching and practicing specific emotion regulation strategies in a given therapy session and linking outcomes to the next session, researchers can take advantage of modular, skills-based treatments to determine the specific and general impact of emotion regulation strategies on a variety of outcomes (Sauer-Zavala et al., 2017). If patients are actively and more intensively practicing one emotion regulation strategy at 
a time, such an assessment timeframe allows for patients to develop some competence in each strategy, while still capturing relatively immediate effects on relevant outcomes.

It remains unclear how emotion regulation effectiveness relates to adaptiveness in treatments. Although more research is needed to fully characterize effective in-session and between-session emotion regulation in treatment, future researchers are encouraged to prioritize the link between in-session and between-session emotion regulation behaviors. Specifically, it is important to know if more effective in-session emotion regulation behaviors promote more adaptive between-session emotion regulation behaviors and if such between-session behaviors can be linked with longer-term adaptiveness. By combining in-session, session-to-session, and pre- to post-treatment measures in multilevel models, researchers can synthesize data across levels of analysis to empirically connect theoretical processes of change in treatment.

\section{Within- vs. Between-Situation Skills Use}

\section{Affective Science Research}

Much of the research discussed so far has concerned the patterns with which people use emotion regulation strategies across a range of situations. However, different situations may provide unique affordances or constraints on a person's strategy use (Suri et al., 2018). This implies that the patterns of emotion regulation people demonstrate across different situations may differ from how they regulate emotions in any given situation. In one study, undergraduate students read 11 hypothetical stressful vignettes and provided free response descriptions of how they would respond in each one (Southward et al., 2018). After responding to all vignettes, participants were asked four more times for each vignette how they would respond if their previous strategy was not working. Participants who described a larger repertoire of strategies across all vignettes reported greater conscientiousness and fewer BPD features. However, in a 
given vignette, participants who described switching strategies more frequently reported lower conscientiousness, higher neuroticism, and more BPD features and depressive symptoms. These results provide some empirical evidence that between-situation emotion regulation differs from within-situation emotion regulation and suggest it may be more adaptive to use a wider range of strategies between situations but persist with fewer strategies within a situation.

The within-situation results in the above study replicate the results from two experimental studies. In one, MTurk participants viewed a disgust-eliciting film clip and reported on their naturalistic use of emotion regulation strategies (Aldao \& Nolen-Hoeksema, 2013). Participants who used more emotion regulation strategies while watching the clip also experienced greater disgust. Further, participants who used more emotion regulation strategies reported using any one of them to a lesser degree than participants who only used a single strategy. In the second study, community participants viewed negatively-valenced images of varying emotional intensities (Birk \& Bonanno, 2016). Participants were instructed to either use cognitive reappraisal or distraction as an initial strategy, but were permitted to switch to the other strategy if they felt like their initial strategy was ineffective. Among participants who initially used reappraisal and who were less sensitive to internal physiological feedback, more frequent strategy switching was associated with lower overall life satisfaction, in line with Aldao and Nolen-Hoeksema (2013) and Southward et al. (2018). However, participants who initially used reappraisal and were more sensitive to their physiological internal feedback reported higher overall life satisfaction when they switched strategies more frequently.

Researchers have conducted five EMA studies to explore these effects naturalistically. ${ }^{2}$ In

\footnotetext{
${ }^{2}$ We note, however, that in these studies, greater "within-situation variability," as the authors operationalize it, indicates that at least one strategy was used a substantial amount and at least one strategy was unused in a given situation. This definition of "within-situation variability" is thus more in line with the extensive use of a single strategy, or lower within-situation variability, than switching between multiple strategies. Thus, to be consistent with
} 
two studies of undergraduates from Singapore, Germany, and Belgium, as well as German adults, lower within-situation variability in emotion regulation strategy use was associated with lower negative affect and neuroticism and higher agreeableness (Blanke et al., 2019; Keng et al., 2018). The strategies assessed in each study are a mix of putatively adaptive and maladaptive strategies, making it difficult to determine whether variability in certain types of strategies are more or less strongly related to adaptive outcomes.

To address this limitation, three EMA studies used factor analyses to classify emotion regulation strategies as relatively adaptive or maladaptive. In three samples of undergraduates, the use of a greater number of adaptive strategies in a given situation was associated with greater positive affect and lower negative affect, dysphoria, and social anxiety, while the use of a greater number of maladaptive strategies in a given situation was associated with lower positive affect and greater negative affect, dysphoria, and social anxiety (McMahon \& Naragon-Gainey, 2019; Roesch et al., 2010; Southward \& Cheavens, 2020a).

Taken together, the results of these studies suggest that greater within-situation variability (i.e., switching between emotion regulation strategies within situations) is associated with less effective outcomes. This may be because people lack clarity about how they feel and are "flailing" for a response by using both adaptive and maladaptive strategies. However, if people are more sensitive to their physiological responses or exclusively using adaptive strategies, greater within-situation variability may be associated with more effective outcomes. Future researchers are encouraged to combine experimental tasks with EMA approaches in samples composed of the full dimension of psychopathology to clarify these results.

\section{Intervention Research}

our presentation of within-situation variability, we will instead refer to results the original authors deemed "greater within-situation variability" as "lower within-situation variability." 
Only one study to our knowledge has directly assessed the within-person use of skills in a treatment-seeking sample (McMahon \& Naragon-Gainey, 2019). Across a 10-day EMA period, only the use of a greater number of maladaptive strategies within a given situation predicted decreases in positive affect and increases in negative affect, dysphoria, social anxiety, worry, and panic - adaptive strategy use was unrelated to outcomes. These results suggest that it may be more efficacious to help patients use fewer maladaptive strategies in a given situation than to encourage them to use several adaptive strategies. Future researchers are encouraged to explicitly test this hypothesis by asking patients to refrain from using maladaptive strategies. Of note, patients in this study were assessed at various points in their treatments, which were not necessarily focused on emotion regulation skills. Thus, future researchers are encouraged to test if the relations between strategy use and emotional outcomes change over treatment as people learn and practice more adaptive strategies. Finally, future researchers may test whether specific emotion regulation strategies are effective within situations, over and above the total number of strategies used to determine if it is the type, rather than number, of strategies that is more important in a given stressful situation.

\section{Order and Timing of Strategy Use}

\section{Affective Science Research}

In addition to the type and number of strategies used within a situation, the order and timing with which these strategies are used may impact both the relative effectiveness of these strategies and the outcome of their combined use (Denny, 2020). Two studies have assessed the naturalistic use of emotion regulation strategies in samples without psychopathology. Across both studies, participants reported temporal patterns of first avoiding, suppressing, or ruminating about negative emotions, followed by reappraising, distracting from, or problem-solving around 
these emotions, and ending with acceptance (Guiller et al., 2019; Kalokerinos et al., 2017).

Interestingly, rumination was more strongly associated with greater negative affect when it was used later in an emotional experience, while reappraisal was more strongly associated with lower negative affect when it was used earlier. Further, acceptance was more likely to be used later in an emotional experience by people average or higher in trait anxiety. Although these results are correlational, they suggest that using emotion regulation strategies outside their typical temporal context may enhance their effects on negative affect, for better or for worse.

The sequential effects of emotion regulation have been most frequently studied in relation to cognitive reappraisal. As described above, only switching from reappraisal to distraction, and not from distraction to reappraisal, in response to increased emotional intensity was related to overall well-being (Birk \& Bonanno, 2016). Undergraduates who ruminated on an angerprovoking event and then reappraised it showed a slightly greater decrease in anger than those who reappraised first and then ruminated and those who only ruminated or reappraised (Peuters et al., 2019). Finally, among adults with MDD, practicing self-compassion and then reappraisal led to greater decreases in negative mood than reappraising after waiting (Diedrich et al., 2016). The authors found mixed results regarding the use of acceptance before reappraisal: although there were no significant differences between the effects of acceptance and self-compassion on reappraisal effectiveness, there also were no significant differences between acceptance and waiting. Together, these results suggest that switching from reappraisal to distraction in response to more intense emotional experiences may be more adaptive in the long term, but switching from rumination or self-compassion to reappraisal may be more effective in the short term.

\section{Intervention Research}

There are mixed and relatively disparate findings of the relation between emotion 
regulation strategy order and timing in treatment studies. In one of the most direct tests of the ordering of emotion regulation skills, Sauer-Zavala et al. (2019) delivered UP modules ordered according to patients' baseline strengths or deficits. Patients who received modules in line with their personal strengths tended to demonstrate more rapid improvement in depression and anxiety. An alternative approach to ordering UP modules is based on the strength of the association between patients' naturalistic, pre-treatment UP-relevant behaviors and clinical symptoms (Fernandez et al., 2017). In this approach, patients report their daily use of UPrelevant behaviors and clinical symptoms using EMA before starting treatment. Behaviors that exhibit the strongest associations with each patient's most central clinical symptoms indicate which modules to prioritize. Using this approach, Fisher et al. (2019) found that prioritizing UP modules with stronger connections to patients' symptoms led to large decreases in anxiety and depression. Further, ordering modules based on expert therapists' reviews of patients' pretreatment data or a purely data-driven algorithm led to similar decreases in symptoms.

Among adults in a DBT-based partial hospital program for eating disorders, patients' use of more DBT skills one month into treatment accounted for 1.58-7.43 times as much variability in improvements in emotion dysregulation, eating disorder symptoms, and depressive symptoms than patients' use of skills later in treatment (Brown et al., 2019). By contrast, the use of more DBT skills early in treatment was associated with increases in life problems in a positive psychotherapy group for undergraduates with severe emotion dysregulation, while the use of fewer maladaptive responses later in treatment was associated with reductions in life problems, BPD features, and depressive symptoms in a DBT skills group (Uliaszek et al., 2018). Together, these results suggest that it may be most efficacious to prioritize the use of more emotion regulation strategies, especially those strategies that are relative strengths or strongly connected 
to patients' symptoms, early in treatment and then prioritize reducing maladaptive strategies later in treatment. Future researchers are encouraged to systematically replicate and extend these results incorporating personalized skill profiles as well as the basic research above to determine the optimal ordering of emotion regulation strategy delivery in treatment.

\section{Improving Self-Efficacy Regarding Emotion Regulation Strategy Use}

Finally, although what strategies patients use and how they use them undoubtedly impact emotional outcomes, these structural dimensions of emotion regulation may only exert their impacts in the context of emotion regulation self-efficacy. Self-efficacy is "the conviction that one can successfully execute the behavior required to produce the outcomes" (Bandura, 1977). Thus, if patients have the conviction that they can successfully apply emotion regulation strategies, they will be more likely to use them and learn how these strategies impact their emotions. Multiple treatments, including CBT for panic disorder (Gallagher et al., 2013), CBT for social anxiety (Goldin et al., 2012), and DBT for BPD (Barnicot et al., 2016), have led to increases in general and emotion regulation self-efficacy. Improvements in self-efficacy have been associated with more frequent use of DBT skills and reduced frequency of NSSI in DBT (Barnicot et al., 2016). Improvements in self-efficacy have also mediated the effects of CBT, versus waitlist, on reductions in social anxiety symptoms and predicted lower social anxiety symptoms one year post-treatment (Goldin et al., 2012). Finally, improvements in self-efficacy have predicted within-person session-to-session decreases in panic symptoms in CBT for panic disorder (Gallagher et al., 2013). Together, these results provide evidence that treatments for emotional disorders enhance emotion regulation self-efficacy, that emotion regulation selfefficacy is related to greater emotion regulation strategy use, and that emotion regulation selfefficacy predicts changes in emotional outcomes at different timescales in treatment. 
It is important to note that, although self-efficacy can promote greater use of emotion regulation strategies, successful emotion regulation strategy use can also enhance self-efficacy (Bandura, 1977). Thus, the perception of emotion regulation success may be an indicator of emotion regulation self-efficacy. Future researchers are encouraged to test this hypothesis in interventions explicitly designed to enhance emotion regulation self-efficacy compared to interventions designed to increase adaptive emotion regulation quantity or quality or decrease maladaptive emotion regulation frequency. Such experimental interventions would provide insight into the relative efficacy and causal processes involved in each approach.

The distinction between emotion regulation self-efficacy and effectiveness is also important to note, as these constructs may be differentially related to emotional outcomes. Daniel et al. (2019) compared perceptions of emotion regulation self-efficacy and effectiveness in an EMA study of undergraduates. Six times per day for two weeks, participants reported their emotion regulation strategy use, positive and negative affect, and the degree to which each strategy improved their mood. Perceived emotion regulation self-efficacy was related to the use of more engagement-oriented, rather than avoidance-oriented, strategies. However, the effectiveness of participants' emotion regulation strategies (i.e., the degree to which participants' mood improved) was related to greater use of avoidance-oriented strategies. In light of the distinction between effectiveness and adaptiveness above, these results suggest that emotion regulation self-efficacy may be more strongly related to adaptiveness than effectiveness. Future researchers may examine whether interventions designed to promote emotion regulation selfefficacy prompt greater improvements in psychopathology symptoms than interventions designed to promote emotion regulation effectiveness.

\section{Contextual Factors}


As noted earlier, contextual factors at multiple levels may influence each of these approaches to intervention. At the most granular level, biological factors may influence how well emotion regulation interventions work for patients. For instance, neural structures, in particular impaired connectivity between cortical (e.g., prefrontal and anterior cingulate cortices) and subcortical (e.g., amygdala) structures, have been associated with greater emotion dysregulation (Banks et al., 2007). More variable psychophysiological responses, such as respiratory sinus arrhythmia (Beauchaine, 2015) and heart rate variability (Appelhans \& Luecken, 2006), have been associated with lower self-reported emotion dysregulation. However, in one treatment study of CBT and ACT, lower heart rate variability was associated with better symptom improvement in both conditions (Davies et al., 2015).

These biological vulnerabilities may transact with patients' developmental trajectories to influence the success of emotion regulation interventions (Crowell et al., 2009; Linehan, 1993). One naturalistic study of DBT for BPD found that patients with a history of childhood trauma demonstrated greater symptom improvements than patients without such a history (McFetridge et al., 2015). Similarly, patients with a history of childhood trauma and those who had experienced more recent life stressors were predicted to have better outcomes in cognitive therapy than interpersonal therapy for depression (van Bronswijk et al., 2019). Capturing patients' developmental trajectories may be important moderators for researchers to consider.

Each instance of emotion regulation occurs in a context of environmental affordances and situational factors. These include the controllability of the stressor eliciting the emotion (Haines et al., 2016; Troy et al., 2013), a person's momentary goals (Millgram et al., 2015), interpersonal surroundings (Dixon-Gordon, Bernecker, \& Christensen, 2015), and emotion type (Southward et al., 2019) and intensity (Dixon-Gordon, Aldao, \& de los Reyes, 2015). Results from these studies 
suggest some form of emotion regulation consistency from one situation to the next. For instance, people with fewer depressive symptoms used reappraisal more often in less controllable situations than more controllable situations (Haines et al., 2016). People also used reappraisal more often in response to less intense emotions and distraction in response to more intense emotions (Sheppes et al., 2014). These examples represent a selection of factors researchers have investigated, although many other factors may be involved (Aldao, 2013). One of the most important targets for researchers in this area is to compare the relative influence of these environmental factors to determine which are particularly impactful and if some contexts prompt more consistent use of certain emotion regulation strategies than others.

Finally, a host of individual difference variables have been assessed by basic affective science and intervention researchers. Factors such as age (Eldesouky \& English, 2018), gender (Nolen-Hoeksema, 2012; Sasso et al., 2015), culture (Ford \& Mauss, 2015), and personality (Gross \& John, 2003; Southward et al., 2018) have all been shown to influence emotion regulation effectiveness and adaptiveness in basic affective science and intervention studies. Most promisingly, researchers have even begun to examine the interactions of contextual variables at multiple levels of analysis simultaneously (e.g., neurological functioning and individual differences in personality; Morawetz et al., 2017). Individual difference variables may be especially important to the tailoring and personalization of emotion regulation interventions. Characterizing for whom different strategies are more, or less, effective or adaptive can facilitate the optimal matching of patients to specific emotion regulation interventions. Although a thorough review of contextual factors implicated in emotion regulation is beyond the scope of the current article, this selection highlights the importance of particular contextual factors alongside each aspect of emotion regulation (Figure 1). 


\section{Concluding Remarks}

The abundance of basic affective science and intervention research on the effects of emotion regulation strategies is vital to the successful treatment of mental health difficulties. By proposing a conceptual framework to delineate the mechanisms by which emotion regulation strategies exert their effects, we hope this body of work can be more effectively synthesized and utilized by researchers to inform the targets of basic affective science and intervention research. As illustrated in Figure 1, we believe it is important to systematically test motivational, betweensituation, and within-situation mechanisms of emotion regulation at short- and long-term time scales. At the motivational level, it is important to understand whether emotion regulation selfefficacy can be targeted directly or whether it results from the successful application of emotion regulation strategies. Although it is depicted at the top of Figure 1, it remains an empirical question whether or under what conditions emotion regulation self-efficacy is necessary to promote improved psychological outcomes. At the between-situation level, a relatively large body of research speaks to the utility of teaching and using a wide variety of emotion regulation strategies across different situations. However, questions remain regarding the mechanisms by which teaching a variety of strategies exert their effects. Given the amount of time invested by patients and therapists in these treatments, systematically comparing different emotion regulation instruction approaches may facilitate the development of more targeted and time-limited interventions. At the within-situation level, although it is relatively well-established that greater negative emotional intensity prompts the use of more strategies, researchers are just starting to understand whether this response is adaptive. Further, given that the use of multiple strategies in a given situation is the rule, not the exception, researchers are beginning to delineate adaptive patterns of strategy use to guide patients. Finally, each of the mechanisms reviewed above may 
exert shorter- and longer-term effects which may differ from one another, so researchers should be clear in their study designs and conclusions about the generalizability of their findings.

\section{Limitations}

The framework of emotion regulation mechanisms and targets reviewed here is by no means the only model of emotion regulation, nor does it address all potential mechanisms and targets involved in treatment enhancement. However, we believe this framework complements established models of emotion regulation in useful ways. For instance, Gross' (2015) extended process model of emotion regulation is inherently a within-situation model of the effectiveness of a single emotion regulation strategy, while Ford et al.'s (2019) model of emotion polyregulation and Bonanno and Burton's (2013) model of regulatory flexibility characterize the within-situation dynamics of the effectiveness of multiple emotion regulation strategies. Gross' (2015) and Ford et al.'s (2019) models explicitly incorporate attentional direction, values-driven choice and behavior, and strategy evaluation in their description of emotion regulation. Bonanno and Burton's (2013) model further adds an awareness of contextual demands and strategy monitoring. Given that these models have primarily been applied to non-treatment contexts, intervention researchers could extend the utility of these models by gathering fine-grained details on the moment-by-moment mechanisms and impacts of emotion regulation strategies in treatment to understand how strategies taught in interventions are learned and applied.

Further, we recognize that emotion regulation is only one process of many that influences the impact of interventions (e.g., Aafjes-van Doorn \& Barber, 2017; Forster et al., 2014; Frank \& Frank, 1993). Although the framework presented here is focused on the implementation of emotion regulation strategies, these strategies will certainly be affected by contextual variables that arise and constitute the milieu of treatment. Researchers interested in these variables (e.g., 
therapeutic alliance; treatment expectations; cultural norms; personality; emotion regulation goals; treatment setting; therapist interpretations) are encouraged to extend this framework by testing the relation between different contexts and emotion regulation. Situating the mechanisms of emotion regulation in a broader contextual model of treatment will provide the most holistic understanding of how to improve the efficacy, efficiency, and outcomes of our treatments.

\section{Future Directions}

Testing the mechanisms of emotion regulation using this translational framework will facilitate our understanding of which mechanisms are most influential in the teaching and use of emotion regulation strategies. This understanding, in turn, will help intervention researchers design more efficient and targeted treatments for the full range of emotional disorders. Systematically testing each mechanism of emotion regulation from Figure 1 will further characterize whether the most salient effects of each mechanism are what we assume them to be. Researchers who simultaneously assess competing explanations (e.g., teaching a wider variety of strategies increases patients' repertoire vs. decreases patients' maladaptive strategy frequency) will be in a position to offer the strongest tests of these hypotheses. We hope that synthesizing the research from basic affective science and intervention research will bring conceptual clarity to the important construct of emotion regulation and enhance the translation of basic science to intervention. Given the centrality of emotion dysregulation to psychopathology, we believe that such conceptual clarity is a key step in developing a mechanistic understanding of how treatments function. Ultimately, this mechanistic and holistic understanding of treatments can be used to develop and adapt treatments to be more targeted, personalized, and disseminable to meet the desperate need for improved mental healthcare. 


\section{References}

Aafjes-van Doorn, K., \& Barber, J. P. (2017). Systematic review of in-session affect experience in cognitive behavioral therapy for depression. Cognitive Therapy and Research, 41(6), 807-828. https://doi.org/10.1007/s10608-017-9865-6

Adler, A. D., Conklin, L. R., \& Strunk, D. R. (2013). Quality of coping skills predicts depressive symptom reactivity over repeated stressors. Journal of Clinical Psychology, 69(12), 1228-1238. https://doi.org/10.1002/jclp.21993

Adler, A. D., Strunk, D. R., \& Fazio, R. H. (2015). What changes in cognitive therapy for depression? An examination of cognitive therapy skills and maladaptive beliefs. Behavior Therapy, 46(1), 96-109. https://doi.org/10.1016/j.beth.2014.09.001

Aldao, A. (2013). The future of emotion regulation research: Capturing context. Perspectives on Psychological Science, 8(2), 155-172. https://doi.org/10.1177/1745691612459518

Aldao, A., Gee, D. G., de los Reyes, A., \& Seager, I. (2016). Emotion regulation as a transdiagnostic factor in the development of internalizing and externalizing psychopathology: Current and future directions. Developmental Psychopathology, 28(4), 927-946. https://doi.org/10.1017/S0954579416000638

Aldao, A., \& Nolen-Hoeksema, S. (2013). One versus many: Capturing the use of multiple emotion regulation strategies in response to an emotion-eliciting stimulus. Cognition and Emotion, 27(4), 753-760. https://doi.org/10.1080/02699931.2012.739998

Aldao, A., Nolen-Hoeksema, S., \& Schweizer, S. (2010). Emotion-regulation strategies across psychopathology: A meta-analytic review. Clinical Psychology Review, 30(2), 217-237. https://doi.org/10.1016/j.cpr.2009.11.004

Aldao, A., Sheppes, G., \& Gross, J. J. (2015). Emotion regulation flexibility. Cognitive Therapy 
and Research, 39, 263-278. https://doi.org/10.1007/s10608-014-9662-4

Appelhans, B. M., \& Luecken, L. J. (2006). Heart rate variability as an index of regulated emotional responding. Review of General Psychology, 10(3), 229-240. https://doi.org/10.1037/1089-2680.10.3.229

Bandura, A. (1977). Self-efficacy: Toward a unifying theory of behavioral change. Psychological Review, 84(2), 191-215. https://doi.org/10.1037/0033-295X.84.2.191

Banks, S. J., Eddy, K. T., Angstadt, M., Nathan, P. J., \& Phan, K. L. (2007). Amygdala-frontal connectivity during emotion regulation. Social Cognitive and Affective Neuroscience, 2(4), 303-312. https://doi.org/10.1093/scan/nsm029

Barber, J. P., \& DeRubeis, R. J. (1992). The Ways of Responding: A scale to assess compensatory skills taught in cognitive therapy. Behavioral Assessment, 14(1), 93-115.

Barber, J. P., \& DeRubeis, R. J. (2001). Change in compensatory skills in cognitive therapy for depression. Journal of Psychotherapy Practice \& Research, 10(1), 8-13.

Barlow, D. H., Sauer-Zavala, S., Farchione, T. J., Murray Latin, H., Ellard, K. E., Bullis, J. R., Bentley, K. H., Boettcher, H. T., \& Cassiello-Robbins, C. (2018). Unified protocol for transdiagnostic treatment of emotional disorders (2nd ed.). Oxford University Press.

Barnicot, K., Gonzalez, R., McCabe, R., \& Priebe, S. (2016). Skills use and common treatment processes in dialectical behaviour therapy for borderline personality disorder. Journal of Behavior Therapy and Experimental Psychiatry, 52, 147-156. https://doi.org/10.1016/j.jbtep.2016.04.006

Beauchaine, T. P. (2015). Respiratory sinus arrhythmia: A transdiagnostic biomarker of emotion dysregulation and psychopathology. Current Opinion in Psychology, 3, 43-47. https://doi.org/10.1016/j.copsyc.2015.01.017 
Beck, A. T., Rush, A. J., Shaw, B. F., \& Emery, G. (1979). Cognitive therapy of depression. Guilford Press.

Berking, M., Ebert, D., Cuijpers, P., \& Hofmann, S. G. (2013). Emotion regulation skills training enhances efficacy of inpatient cognitive behavior therapy for major depressive disorder: A randomized controlled trial. Psychotherapy and Psychosomatics, 82, 234-245. https://doi.org/10.1159/000348448

Berking, M., Eichler, E., Luhmann, M., Diedrich, A., Hiller, W., \& Rief, W. (2019). Affect regulation training reduces symptom severity in depression - A randomized controlled trial. PLoS One, 14(8), e0220436. https://doi.org/10.1371/journal.pone.0220436

Berking, M., \& Lucas, C. A. (2015). The Affect Regulation Training (ART): A transdiagnostic approach to the prevention and treatment of mental disorders. Current Opinion in Psychology, 3, 64-69. https://doi.org/10.1016/j.copsyc.2015.02.002

Berking, M., Wupperman, P., Reichardt, A., Pejic, T., Dippel, A., \& Znoj, H. (2008). Emotionregulation skills as a treatment target in psychotherapy. Behaviour Research and Therapy, 46(11), 1230-1237. https://doi.org/10.1016/j.brat.2008.08.005

Birk, J. L., \& Bonanno, G. A. (2016). When to throw the switch: The adaptiveness of modifying emotion regulation strategies based on affective and physiological feedback. Emotion, 16(5), 657-670. https://doi.org/10.1037/emo0000157

Blanke, E. S., Brose, A., Kalokerinos, E. K., Erbas, Y., Riediger, M., \& Kuppens, P. (2019). Mix it to fix it: Emotion regulation variability in daily life. Emotion. Advance online publication. https://doi.org/10.1037/emo0000566

Bonanno, G. A., \& Burton, C. L. (2013). Regulatory flexibility: An individual differences perspective on coping and emotion regulation. Perspectives on Psychological Science, 


\section{8(6), 591-612. https://doi.org/10.1177/1745691613504116}

Bonanno, G. A., Papa, A., Lalande, K., Westphal, M., \& Coifman, K. (2004). The importance of being flexible: The ability to both enhance and suppress emotional expression predicts long-term adjustment. Psychological Science, 15(7), 482-487. https://doi.org/10.1111/j.0956-7976.2004.00705.x

Brown, T. A., Cusack, A., Anderson, L., Reilly, E. E., Berner, L. A., Wierenga, C. E., Lavender, J. M., \& Kaye, W. H. (2019). Early versus later improvements in dialectical behavior therapy skills use and treatment outcome in eating disorders. Cognitive Therapy and Research, 43(4), 759-768. https://doi.org/10.1007/s10608-019-10006-1

Carpenter, R. W., \& Trull, T. J. (2013). Components of emotion dysregulation in borderline personality disorder: A review. Current Psychiatry Reports, 15, 335. https://doi.org/10.1007/s11920-012-0335-2

Carver, C. S., Scheier, M. F., \& Weintraub, J. K. (1989). Assessing coping strategies: A theoretically based approach. Journal of Personality and Social Psychology, 56(2), 267283. https://doi.org/10.1037//0022-3514.56.2.267

Cheng, C., Lau, H. P., \& Chan, M. P. (2014). Coping flexibility and psychological adjustment to stressful life changes: A meta-analytic review. Psychological Bulletin, 140(6), 15821607. https://doi.org/10.1037/a0037913

Chugani, C. D., Ghali, M. N., \& Brunner, J. (2013). Effectiveness of short term Dialectical Behavior Therapy skills training in college students with cluster B personality disorders. Journal of College Student Psychotherapy, 27(4), 323-336. https://doi.org/10.1080/87568225.2013.824337

Cipriano, A., Cella, S., \& Cotrufo, P. (2017). Nonsuicidal self-injury: A systematic review. 
Frontiers in Psychology, 8, 1946. https://doi.org/10.3389/fpsyg.2017.01946

Conklin, L. R., Cassiello-Robbins, C., Brake, C. A., Sauer-Zavala, S., Farchione, T. J., Ciraulo, D. A., \& Barlow, D. H. (2015). Relationships among adaptive and maladaptive emotion regulation strategies and psychopathology during the treatment of comorbid anxiety and alcohol use disorders. Behaviour Research and Therapy, 73, 124-130.

\section{https://doi.org/10.1016/j.brat.2015.08.001}

Conklin, L. R., \& Strunk, D. R. (2015). A session-to-session examination of homework engagement in cognitive therapy for depression: Do patients experience immediate benefits? Behaviour Research and Therapy, 72, 56-62. https://doi.org/10.1016/j.brat.2015.06.011

Cristea, I. A., Gentili, C., Cotet, C. D., Palomba, D., Barbui, C., \& Cuijpers, P. (2017). Efficacy of psychotherapies for borderline personality disorder: A systematic review and metaanalysis. JAMA Psychiatry, 74(4), 319-328.

\section{https://doi.org/10.1001/jamapsychiatry.2016.4287}

Crowell, S. E., Beauchaine, T. P., \& Linehan, M. M. (2009). A biosocial developmental model of borderline personality: Elaborating and extending Linehan's theory. Psychological Bulletin, 135(3), 495-510. https://doi.org/10.1037/a0015616

Cuijpers, P., Berking, M., Andersson, G., Quigley, L., Kleiboer, A., \& Dobson, K. S. (2013). A meta-analysis of cognitive-behavioural therapy for adult depression, alone and in comparison with other treatments. Canadian Journal of Psychiatry, 58(7), 376-385. https://doi.org/10.1177/070674371305800702

Cuijpers, P., Cristea, I. A., Karyotaki, E., Reijnders, M., \& Hollon, S. D. (2019). Component studies of psychological treatments of adult depression: A systematic review and meta- 
analysis. Psychotherapy Research, 29(1), 15-29.

\section{https://doi.org/10.1080/10503307.2017.1395922}

Daniel, K. E., Baee, S., Boukhechba, M., Barnes, L. E., \& Teachman, B. A. (2019). Do I really feel better? Effectiveness of emotion regulation strategies depends on the measure and social anxiety. Depression and Anxiety, 36(12), 1182-1190.

https://doi.org/10.1002/da.22970

Daros, A. R., \& Williams, G. E. (2019). A meta-analysis and systematic review of emotionregulation strategies in borderline personality disorder. Harvard Review of Psychiatry, 27(4), 217-232. https://doi.org/10.1097/HRP.0000000000000212

Davies, C. D., Niles, A. N., Pittig, A., Arch, J. J., \& Craske, M. G. (2015). Physiological and behavioral indices of emotion dysregulation as predictors of outcome from cognitive behavioral therapy and acceptance and commitment therapy for anxiety. Journal of Behavior Therapy and Experimental Psychiatry, 46, 35-43. https://doi.org/10.1016/j.jbtep.2014.08.002

Denny, B. T. (2020). Getting better over time: A framework for examining the impact of emotion regulation training. Emotion, 20(1), 110-114. https://doi.org/10.1037/emo0000641

Diedrich, A., Hofmann, S. G., Cuijpers, P., \& Berking, M. (2016). Self-compassion enhances the efficacy of explicit cognitive reappraisal as an emotion regulation strategy in individuals with major depressive disorder. Behaviour Research and Therapy, 82, 1-10. https://doi.org/10.1016/j.brat.2016.04.003

Dixon-Gordon, K. L., Aldao, A., \& De Los Reyes, A. (2014). Repertoires of emotion regulation: A person-centered approach to assessing emotion regulation strategies and links to 
psychopathology. Cognition and Emotion, 29(7), 1314-1325.

\section{https://doi.org/10.1080/02699931.2014.983046}

Dixon-Gordon, K. L., Aldao, A., \& De Los Reyes, A. (2015). Emotion regulation in context:

Examining the spontaneous use of strategies across emotional intensity and type of emotion. Personality and Individual Differences, 86, 271-276.

https://doi.org/10.1016/j.paid.2015.06.011

Dixon-Gordon, K. L., Bernecker, S., \& Christensen, K. (2015). Recent innovations in the field of interpersonal emotion regulation. Current Opinion in Psychology, 3, 36-42. https://doi.org/10.1016/j.copsyc.2015.02.001

Dixon-Gordon, K. L., Chapman, A. L., \& Turner, B. J. (2015). A preliminary pilot study comparing Dialectical Behavior Therapy emotion regulation skills with interpersonal effectiveness skills and a control group treatment. Journal of Experimental Psychopathology, 6(4), 369-388. https://doi.org/10.5127/jep.041714

Ekers, D., Webster, L., Van Straten, A., Cuijpers, P., Richards, D., \& Gilbody, S. (2014). Behavioural activation for depression; An update of meta-analysis of effectiveness and sub group analysis. PLoS One, 9(6), e100100. https://doi.org/10.1371/journal.pone.0100100

Eldesouky, L., \& English, T. (2018). Another year older, another year wiser? Emotion regulation strategy selection and flexibility across adulthood. Psychology and Aging, 33(4), 572585. https://doi.org/10.1037/pag0000251

Fernandez, K. C., Fisher, A. J., \& Chi, C. (2017) Development and initial implementation of the Dynamic Assessment Treatment Algorithm (DATA). PLoS ONE, 12(6), e0178806. https://doi.org/10.1371/journal.pone.0178806 
Fisher, A. J., Bosley, H. G., Fernandez, K. C., Reeves, J. W., Soyster, P. D., Diamond, A. E., \& Barkin, J. (2019). Open trial of a personalized modular treatment for mood and anxiety. Behaviour Research and Therapy, 116, 69-79. https://doi.org/10.1016/j.brat.2019.01.010

Flynn, D., Kellis, M., Joyce, M., Corcoran, P., Hurley, J., Gillespie, C., Suarez, C., Swales, M., \& Arensman, E. (2018). Multisite implementation and evaluation of 12-month standard Dialectical Behavior Therapy in a public community setting. Journal of Personality Disorders, 34(3), 377-393. https://doi.org/10.1521/pedi_2018_32_402

Folkman, S., \& Lazarus, R. S. (1988). The relationship between coping and emotion: Implications for theory and research. Social Science \& Medicine, 26(3), 309-317. https://doi.org/10.1016/0277-9536(88)90395-4

Forand, N. R., Barnett, J. G., Strunk, D. R., Hindiyeh, M. U., Feinberg, J. E., \& Keefe, J. R. (2018). Efficacy of guided iCBT for depression and mediation of change by cognitive skill acquisition. Behavior Therapy, 49(2), 295-307. https://doi.org/10.1016/j.beth.2017.04.004

Ford, B. Q., Gross, J. J., \& Gruber, J. (2019). Broadening our field of view: The role of emotion polyregulation. Emotion Review, 11(3), 197-208. https://doi.org/10.1177/1754073919850314

Ford, B. Q., \& Mauss, I. B. (2015). Culture and emotion regulation. Current Opinion in Psychology, 3, 1-5. https://doi.org/10.1016/j.copsyc.2014.12.004

Forster, C., Berthollier, N., \& Rawlinson, D. (2014). A systematic review of potential mechanisms of change in psychotherapeutic interventions for personality disorder. Journal of Psychology and Psychotherapy, 4, 1-14. https://doi.org/10.4172/2161$\underline{0487.1000133}$ 
Frank, J. D., \& Frank, J. B. (1993). Persuasion and healing: A comparative study of psychotherapy (3rd ed.). Johns Hopkins University Press.

Gallagher, M. W., Payne, L. A., White, K. S., Shear, K. M., Woods, S. W., Gorman, J. M., \& Barlow, D. H. (2013). Mechanisms of change in cognitive behavioral therapy for panic disorder: The unique effects of self-efficacy and anxiety sensitivity. Behaviour Research and Therapy, 51(11), 767-777. https://doi.org/10.1016/j.brat.2013.09.001

Gibbons, M. B. C., Crits-Cristoph, P., Barber, J. P., Wiltsey Stirman, S., Gallop, R., Goldstein, L. A., Temes, C. M., \& Ring-Kurtz, S. (2009). Unique and common mechanisms of change across cognitive and dynamic psychotherapies. Journal of Consulting and Clinical Psychology, 77(5), 801-813. https://doi.org/10.1037/a0016596

Goldin, P. R., Ziv, M., Jazaieri, H., Werner, K., Kraemer, H., Heimberg, R. G., \& Gross, J. J. (2012). Cognitive reappraisal self-efficacy mediates the effects of individual cognitivebehavior therapy for social anxiety disorder. Journal of Consulting and Clinical Psychology, 80(6), 1034-1040. https://doi.org/10.1037/a0028555

Gratz, K. L., \& Gunderson, J. G. (2006). Preliminary data on an acceptance-based emotion regulation group intervention for deliberate self-harm among women with borderline personality disorder. Behavior Therapy, 37(1), 25-35. https://doi.org/10.1016/j.beth.2005.03.002

Gratz, K. L., Tull, M. T., \& Levy, R. (2014). Randomized controlled trial and uncontrolled 9month follow-up of an adjunctive emotion regulation group therapy for deliberate selfharm among women with borderline personality disorder. Psychological Medicine, 44(10), 2099-2112. https://doi.org/10.1017/S0033291713002134

Gratz, K. L., Weiss, N. H., \& Tull, M. T. (2015). Examining emotion regulation as an outcome, 
mechanism, or target of psychological treatments. Current Opinion in Psychology, 3, 8590. https://doi.org/10.1016/j.copsyc.2015.02.010

Gross, J. J. (2015). Emotion regulation: Current status and future prospects. Psychological Inquiry, 26, 1-26. https://doi.org/10.1080/1047840X.2014.940781

Gross, J. J., \& John, O. P. (2003). Individual differences in two emotion regulation processes: Implications for affect, relationships, and well-being. Journal of Personality and Social Psychology, 85(2), 348-362. https://doi.org/10.1037/0022-3514.85.2.348

Gross, J. J., \& Thompson, R. A. (2007). Emotion regulation: Conceptual foundations. In J. J. Gross (Ed.), Handbook of emotion regulation (3-24). Guilford Press.

Guiller, T., Dauvier, B., Pavani, J.-B., Hichem Chakri, K., \& Congard, A. (2019). 'It might be time to accept'. Exploring the dynamics between affect regulation strategies, anxiety and timing of regulation. Personality and Individual Differences, 142, 21-27. https://doi.org/10.1016/j.paid.2019.01.023

Haines, S. J., Gleeson, J., Kuppens, P., Hollenstein, T., Ciarrochi, J., Labuschagne, I., Grace, C., \& Koval, P. (2016). The wisdom to know the difference: Strategy-situation fit in emotion regulation in daily life is associated with well-being. Psychological Science, 27(12), 1651-1659. https://doi.org/10.1177/0956797616669086

Hamza, C. A., \& Willoughby, T. (2015). Nonsuicidal self-injury and affect regulation: Recent findings from experimental and ecological momentary assessment studies and future directions. Journal of Clinical Psychology, 71(6), 561-574. https://doi.org/10.1002/jclp.22174

Heiy, J. E., \& Cheavens, J. S. (2013). Back to basics: A naturalistic assessment of the experience and regulation of emotion. Emotion, 14(5), 878-891. https://doi.org/10.1037/a0037231 
Hundt, N. E., Mignogna, J., Underhill, C., \& Cully, J. A. (2013). The relationship between use of CBT skills and depression treatment outcome: A theoretical and methodological review of the literature. Behavior Therapy, 44(1), 12-26. https://doi.org/10.1016/j.beth.2012.10.001

Kalokerinos, E. K., Résibois, M., Verduyn, P., \& Kuppens, P. (2017). The temporal deployment of emotion regulation strategies during negative emotional episodes. Emotion, 17(3), 450-458. https://doi.org/10.1037/emo0000248

Keng, S.-L., Choo, X., \& Tong, E. M. W. (2018). Association between trait mindfulness and variability of coping strategies: A diary study. Mindfulness, 9(5), 1423-1432. https://doi.org/10.1007/s12671-018-0885-4

Khoury, B., Lecomte, T., Fortin, G., Masse, M., Therien, P., Bouchard, V., Chapleau, M. A., Paquin, K., \& Hofmann, S. G. (2013). Mindfulness-based therapy: A comprehensive meta-analysis. Clinical Psychology Review, 33, 763-771. https://doi.org/10.1016/j.cpr.2013.05.005

Klonsky, E. D. (2007). The functions of deliberate self-injury: A review of the evidence. Clinical Psychology Review, 27, 226-239. https://doi.org/10.1016/j.cpr.2006.08.002

Klonsky, E. D., May, A. M., \& Glenn, C. R. (2013). The relationship between nonsuicidal selfinjury and attempted suicide: Converging evidence from four samples. Journal of Abnormal Psychology, 122(1), 231-237. https://doi.org/10.1037/a0030278

Kring, A. M., \& Sloan, D. M. (2010). Emotion regulation and psychopathology: A transdiagnostic approach to etiology and treatment. Guilford Press.

Kuyken, W., Watkins, E., Holden, E., White, K., Taylor, R. S., Byford, S., Evans, A., Radford, S., Teasdale, J. D., \& Dalgleish, T. (2010). How does mindfulness-based cognitive 
therapy work? Behaviour Research and Therapy, 48, 1105-1112. https://doi.org/10.1016/j.brat.2010.08.003

Linehan, M. M. (1993). Cognitive-behavioral treatment of borderline personality disorder. Guilford Press.

Linehan, M. M., Korslund, K. E., Harned, M. S., Gallop, R. J., Lungu, A., Neacsiu, A. D., McDavid, J., Comtois, K. A., \& Murray-Gregory, A. M. (2015). Dialectical behavior therapy for high suicide risk in individuals with borderline personality disorder: A randomized clinical trial and component analysis. JAMA Psychiatry, 72(5), 475-482. https://doi.org/10.1001/jamapsychiatry.2014.3039

Lukas, C. A., Ebert, D. D., Fuentes, H. T., Caspar, F., \& Berking, M. (2018). Deficits in general emotion regulation skills - Evidence of a transdiagnostic factor. Journal of Clinical Psychology, 74(6), 1017-1033. https://doi.org/10.1002/jclp.22565

Manber, R., Arnow, B., Blasey, C., Vivian, D., McCullough, J. P., Blalock, J. A., Klein, D. N., Markowitz, J. C., Riso, L. P., Rothbaum, B., Rush, A. J., Thase, M. E., \& Keller, M. B. (2003). Patient's therapeutic skill acquisition and response to psychotherapy, alone or in combination with medication. Psychological Medicine, 33(4), 693-702. https://doi.org/10.1017/S0033291703007608

McFetridge, M. A., Milner, R., Gavin, V., \& Levita, L. (2015). Borderline personality disorder: Patterns of self-harm, reported childhood trauma and clinical outcome. BJPsych Open, 1(1), 18-20. https://doi.org/10.1192/bjpo.bp.115.000117

McMahon, T. P., \& Naragon-Gainey, K. (2019). The multilevel structure of daily emotionregulation-strategy use: An examination of within- and between-person associations in naturalistic settings. Clinical Psychological Science, 7(2), 321-339. 


\section{https://doi.org/10.1177/2167702618807408}

Millgram, Y., Joormann, J., Huppert, J. D., \& Tamir, M. (2015). Sad as a matter of choice? Emotion-regulation goals in depression. Psychological Science, 26(8), 1216-1228. https://doi.org/10.1177/0956797615583295

Moore, K. E., Folk, J. B., Boren, E. A., Tangney, J. P., Fischer, S., \& Schrader, S. W. (2018). Pilot study of a brief Dialectical Behavior Therapy skills group for jail inmates. Psychological Services, 15(1), 98-108. https://doi.org/10.1037/ser0000105

Morawetz, C., Alexandrowicz, R. W., \& Heekeren, H. R. (2017). Successful emotion regulation is predicted by amygdala activity and aspects of personality: A latent variable approach. Emotion, 17(3), 421-441. https://doi.org/10.1037/emo0000215

Muhomba, M., Chugani, C. D., Uliaszek, A. A., \& Kannan, D. (2017). Distress tolerance skills for college students: A pilot investigation of a brief DBT skills training program. Journal of College Student Psychotherapy, 31(3), 247-256. https://doi.org/10.1080/87568225.2017.1294469

Neacsiu, A. D., Bohus, M., \& Linehan, M. M. (2013). Dialectical behavior therapy skills: An intervention for emotion dysregulation. In J. J. Gross (Ed.), Vol. 2. Handbook of emotion regulation (pp. 491-508). Guilford Press.

Neacsiu, A. D., Eberle, J. W., Kramer, R., Wiesmann, T., \& Linehan, M. M. (2014). Dialectical behavior therapy skills for transdiagnostic emotion dysregulation: A pilot randomized controlled trial. Behaviour Research and Therapy, 59, 40-51. https://doi.org/10.1016/j.brat.2014.05.005

Neacsiu, A. D., Rizvi, S. L., \& Linehan, M. M. (2010). Dialectical behavior therapy skills as a mediator and outcome of treatment for borderline personality disorder. Behaviour 
Research and Therapy, 48, 832-839. https://doi.org/10.1016/j.brat.2010.05.017

Neacsiu, A. D., Rizvi, S. L., Vitaliano, P. P., Lynch, T. R., \& Linehan, M. M. (2010). The dialectical behavior therapy ways of coping checklist: Development and psychometric properties. Journal of Clinical Psychology, 66(6), 563-582. https://doi.org/10.1002/jclp.20685

Neacsiu, A. D., \& Tkachuck, M. A. (2016). Dialectical behavior therapy skills use and emotion dysregulation in personality disorders and psychopathy: A community self-report study. Borderline Personality Disorder and Emotion Dysregulation, 3, 6. https://doi.org/10.1186/s40479-016-0041-5

Neimeyer, R. A., \& Feixas, G. (1990). The role of homework and skill acquisition in the outcome of group cognitive therapy for depression. Behavior Therapy, 21(3), 281-292. https://doi.org/10.1016/S0005-7894(05)80331-4

Neimeyer, R. A., Kazantzis, N., Kassler, D. M., Baker, K. D., \& Fletcher, R. (2008). Group cognitive behavioural therapy for depression outcomes predicted by willingness to engage in homework, compliance with homework, and cognitive restructuring skill acquisition. Cognitive Behaviour Therapy, 37(4), 199-215. https://doi.org/10.1080/16506070801981240

Nolen-Hoeksema, S. (2012). Emotion regulation and psychopathology: The role of gender. Annual Review of Clinical Psychology, 8, 161-187. https://doi.org/10.1146/annurevclinpsy-032511-143109

O’Brien, C. P. (2011). Drug addiction. In L. Brunton, B. Chabner, \& B. Knollman (Eds.), Goodman \& Gilman's The Pharmacological Basis of Therapeutics (pp. 649-668). McGraw-Hill. 
Opitz, P. C., Cavanagh, S. R., \& Urry, H. L. (2015). Unstructured emotion regulation choice in four studies of cognitive reappraisal. Personality and Individual Differences, 86, 455464. https://doi.org/10.1016/j.paid.2015.06.048

Peuters, C., Kalokerinos, E. K., Lee Pe, M., \& Kuppens, P. (2019). Sequential effects of reappraisal and rumination on anger during recall of an anger-provoking event. PLoS ONE, 14(1), e0209029. https://doi.org/10.1371/journal.pone.0209029

Radkovsky, A., McArdle, J. J., Bockting, C. L. H., \& Berking, M. (2014). Successful emotion regulation skills application predicts subsequent reduction of symptom severity during treatment of major depressive disorder. Journal of Consulting and Clinical Psychology, 82(2), 248-262. https://doi.org/10.1037/a0035828

Renna, M. E., Quintero, J. M., Fresco, D. M., \& Mennin, D. S. (2017). Emotion regulation therapy: A mechanism-targeted treatment for disorders of distress. Frontiers in Psychology, 8, 98. https://doi.org/10.3389/fpsyg.2017.00098

Roesch, S. C., Aldridge, A. A., Stocking, S. N., Villodas, F., Leung, Q., Bartley, C. E., \& Black, L. J. (2010). Multilevel factor analysis and structural equation modeling of daily diary coping data: Modeling trait and state variation. Multivariate Behavioral Research, 45(5), 767-789. https://doi.org/10.1080/00273171.2010.519276

Rodin, R., Bonanno, G. A., Rahman, N., Kouri, N. A., Bryant, R. A., Marmar, C. R., \& Brown, A. D. (2017). Expressive flexibility in combat veterans with posttraumatic stress disorder and depression. Journal of Affective Disorders, 207, 236-241. https://doi.org/10.1016/j.jad.2016.09.027

Sasso, K. E., Strunk, D. R., Braun, J. D., DeRubeis, R. J., \& Brotman, M. A. (2015). Identifying moderators of the adherence-outcome relation in cognitive therapy for depression. 
Journal of Consulting and Clinical Psychology, 83(5), 976-984. https://doi.org/10.1037/ccp0000045

Sauer-Zavala, S., Cassiello-Robbins, C., Ametaj, A. A., Wilner, J. G., \& Pagan, D. (2019). Transdiagnostic treatment personalization: The feasibility of ordering unified protocol modules according to patient strengths and weaknesses. Behavior Modification, 43(4), 518-543. https://doi.org/10.1177/0145445518774914

Sauer-Zavala, S., Cassiello-Robbins, C., Conklin, L., Bullis, J. R., Thompson-Hollands, J., \& Kennedy, K. (2017). Isolating the unique effects of the Unified Protocol treatment modules using single-case experimental design. Behavior Modification, 41(2), 286-307. https://doi.org/10.1177/0145445516673827

Sakiris, N., \& Berle, D. (2019). A systematic review and meta-analysis of the Unified Protocol as a transdiagnostic emotion regulation based intervention. Clinical Psychology Review, 72, 101751. https://doi.org/10.1016/j.cpr.2019.101751

Schmidt, I. D., Pfeifer, B. J., \& Strunk, D. R. (2019). Putting the "cognitive" back in cognitive therapy: Sustained cognitive change as a mediator of in-session insights and depressive symptom improvement. Journal of Consulting and Clinical Psychology, 87(5), 446-456. https://doi.org/10.1037/ccp0000392

Schulze, L., Schmahl, C., \& Niedtfeld, I. (2016). Neural correlates of disturbed emotion processing in borderline personality disorder: A multimodal meta-analysis. Biological Psychiatry, 79(2), 97-106. https://doi.org/10.1016/j.biopsych.2015.03.027

Sheppes, G., Scheibe, S., Suri, G., Radu, P., Blechert, J., \& Gross, J. J. (2014). Emotion regulation choice: A conceptual framework and supporting evidence. Journal of Experimental Psychology: General, 143(1), 163-181. https://doi.org/10.1037/a0030831 
Sloan, E., Hall, K., Moulding, R., Bryce, S., Mildred, H., \& Staiger, P. K. (2017). Emotion regulation as a transdiagnostic treatment construct across anxiety, depression, substance, eating and borderline personality disorders: A systematic review. Clinical Psychology Review, 57, 141-163. https://doi.org/10.1016/j.cpr.2017.09.002

Southward, M. W., Altenburger, E. M., Moss, S. A., Cregg, D. R., \& Cheavens, J. S. (2018). Flexible, yet firm: A model of healthy emotion regulation. Journal of Social and Clinical Psychology, 37(4), 231-251. https://doi.org/10.1521/jscp.2018.37.4.231

Southward, M. W., \& Cheavens, J. S. (2017). Assessing the relation between flexibility in emotional expression and symptoms of anxiety and depression: The roles of context sensitivity and feedback sensitivity. Journal of Social and Clinical Psychology, 36(2), 142-157. https://doi.org/10.1521/jscp.2017.36.2.142

Southward, M. W., \& Cheavens, J. S. (2020a). More (of the right strategies) is better: Disaggregating the naturalistic between- and within-person structure and effects of emotion regulation strategies. Cognition \& Emotion. Advance online publication. https://doi.org/10.1080/02699931.2020.1797637

Southward, M. W., \& Cheavens, J. S. (2020b). Quality or quantity? A multistudy analysis of emotion regulation skills deficits associated with Borderline Personality Disorder. Personality Disorders: Theory, Research, \& Treatment, 11(1), 24-35. https://doi.org/10.1037/per0000357

Southward, M. W., Heiy, J. E., \& Cheavens, J. S. (2019). Emotions as context: Do the naturalistic effects of emotion regulation strategies depend on the regulated emotion? Journal of Social and Clinical Psychology, 38(6), 451-474. https://doi.org/10.1521/jscp.2019.38.6.451 
Southward, M. W., Wilson, A. C., \& Cheavens, J. S. (2020). On what do therapists agree? Assessing therapist evaluations of emotion regulation strategy effectiveness. Psychology and Psychotherapy: Theory, Research, and Practice. Advance online publication. https://doi.org/10.1111/papt.12302

Strunk, D. R., DeRubeis, R. J., Chiu, A. W., \& Alvarez, J. (2007). Patients' competence in and performance of cognitive therapy skills: Relation to the reduction of relapse risk following treatment for depression. Journal of Consulting and Clinical Psychology, 75(4), 523-530. https://doi.org/10.1037/0022-006X.75.4.523

Strunk, D. R., Hollars, S. N., Adler, A. D., Goldstein, L. A., \& Braun, J. D. (2014). Assessing patients' cognitive therapy skills: Initial evaluation of the Competencies of Cognitive Therapy Scale. Cognitive Therapy and Research, 38(5), 559-569. https://doi.org/10.1007/s10608-014-9617-9

Suri, G., Sheppes, G., Young, G., Abraham, D., McRae, K., \& Gross, J. J. (2018). Emotion regulation choice: The role of environmental affordances. Cognition and Emotion, 32(5), 963-971. https://doi.org/10.1080/02699931.2017.1371003

Swales, M., \& Dunkley, C. (2019). Principles of skills assessment in dialectical behavior therapy. Cognitive and Behavioral Practice, 27(1), 18-29. https://doi.org/10.1016/j.cbpra.2019.05.001

Thompson, R. J., Mata, J., Jaeggi, S. M., Buschkuehl, M., Jonides, J., \& Gotlib, H. (2010). Maladaptive coping, adaptive coping, and depressive symptoms: Variations across age and depressive state. Behaviour Research and Therapy, 48, 459-466. https://doi.org/10.1016/j.brat.2010.01.007

Troy, A. S., Shallcross, A. J., \& Mauss, I. B. (2013). A person-by-situation approach to emotion 
regulation: Cognitive reappraisal can either help or hurt, depending on the context. Psychological Science, 24(12), 2505-2514. https://doi.org/10.1177/0956797613496434

Uliaszek, A. A., Hamdullahpur, K., Chugani, C. D., \& Rashid, T. (2018). Mechanisms of change in group therapy for treatment-seeking university students. Behaviour Research and Therapy, 109, 10-17. https://doi.org/10.1016/j.brat.2018.07.006

Uliaszek, A. A., Rashid, T., Williams, G. E., \& Gulamani, T. (2016). Group therapy for university students: A randomized controlled trial of dialectical behavior therapy and positive psychotherapy. Behaviour Research and Therapy, 77, 78-85. https://doi.org/10.1016/j.brat.2015.12.003

Valentine, S. E., Bankoff, S. M., Poulin, R. M., Reidler, E. B., \& Pantalone, D. W. (2015). The use of Dialectical Behavior Therapy skills training as stand-alone treatment: A systematic review of the treatment outcome literature. Journal of Clinical Psychology, 71(1), 1-20. https://doi.org/10.1002/jclp.22114

van Bronswijk, S. C., DeRubeis, R. J., Lemmens, L. H. J. M., Peeters, F. P. M. L., Keefe, J. R., Cohen, Z. D., \& Huibers, M. J. H. (2019). Precision medicine for long-term depression outcomes using the Personalized Advantage Index approach: Cognitive therapy or interpersonal psychotherapy? Psychological Medicine. Advance online publication. https://doi.org/10.1017/S0033291719003192

Vitaliano, P. P., Maiuro, R. D., Russo, J., \& Becker, J. (1987). Raw versus relative scores in the assessment of coping strategies. Journal of Behavioral Medicine, 10(1), 1-18. https://doi.org/10.1007/BF00845124

Webb, C. A., Beard, C., Kertz, S. J., Hsu, K., \& Björgvinsson, T. (2016). Differential role of CBT skills, DBT skills and psychological flexibility in predicting depressive versus 
anxiety symptom improvement. Behaviour Research and Therapy, 81, 12-20. https://doi.org/10.1016/j.brat.2016.03.006

Webb, C. A., Stanton, C. H., Bondy, E., Singleton, P., Pizzagalli, D. A., \& Auerbach, R. P. (2019). Cognitive versus behavioral skills in CBT for depressed adolescents:

Disaggregating within-patient versus between-patient effects on symptom change. Journal of Consulting and Clinical Psychology, 87(5), 484-490. https://doi.org/10.1037/ccp0000393

Webb, T. L., Miles, E., \& Sheeran, P. (2012). Dealing with feeling: A meta-analysis of the effectiveness of strategies derived from the process model of emotion regulation. Psychological Bulletin, 138(4), 775-808. https://doi.org/10.1037/a0027600

Westphal, M., Seivert, N. H., \& Bonanno, G. A. (2010). Expressive flexibility. Emotion, 10(1), 92-100. https://doi.org/10.1037/a0018420

Wilks, C. R., Korslund, K. E., Harned, M. E., \& Linehan, M. M. (2016). Dialectical behavior therapy and domains of functioning over two years. Behaviour Research and Therapy, 77, 162-169. https://doi.org/10.1016/j.brat.2015.12.013

Wirtz, C. M., Radkovsky, A., Ebert, D. D., \& Berking, M. (2014). Successful application of adaptive emotion regulation skills predicts subsequent reduction of depressive symptom severity but neither the reduction of anxiety nor the reduction of general distress during the treatment of major depressive disorder. PLoS ONE, 9(10), e108288. https://doi.org/10.1371/journal.pone.0108288

Zhu, Z., \& Bonanno, G. A. (2017). Affective flexibility: Relations to expressive flexibility, feedback, and depression. Clinical Psychological Science, 5(6), 930-942. https://doi.org/10.1177/2167702617717337 


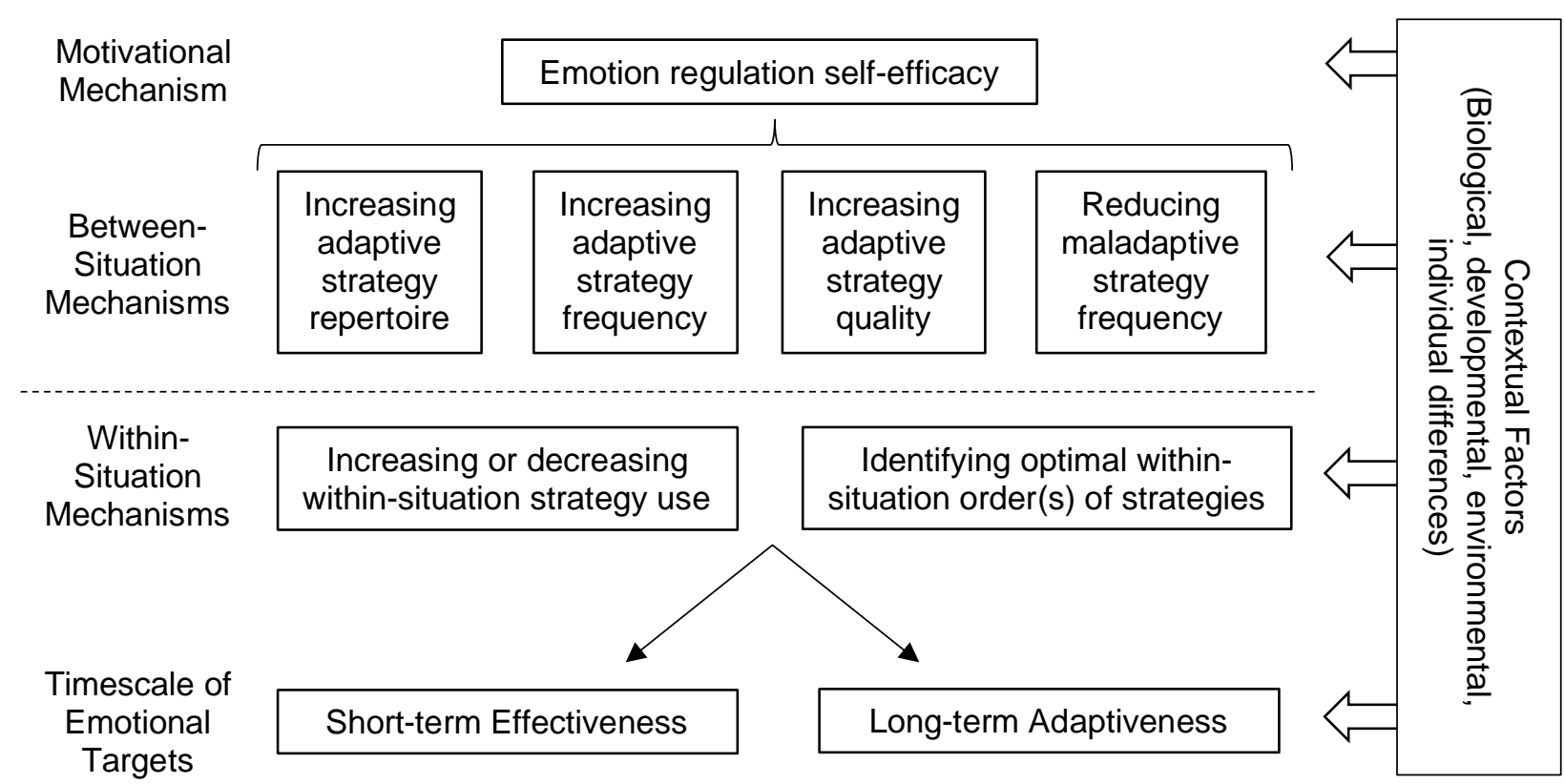

Figure 1. A framework of specific emotion regulation mechanisms and their targets. 